United States

Department of

Agriculture

Forest Service

ForEST SERVICG

Southern

Research Station
Sampling Throughfall and Stemflow in Young Loblolly Pine Plantations

S.J. Zarnoch, D.A. Abrahamson, and P.M. Dougherty

Research Paper

SRS-27 


\section{The Authors}

S. J. Zarnoch, Mathematical Statistician, USDA Forest Service, Southern Research Station, Asheville, NC; D.A. Abrahamson, Hydrologist, USDA Agricultural Research Service, J. Phil Campbell Sr. Natural Resource Conservation Center, Watkinsville, GA; and P.M. Dougherty, Plantation Productivity Project Leader, Westvaco, Summerville, SC, respectively. 


\title{
Sampling Throughfall and Stemflow in Young Loblolly Pine Plantations
}

\author{
S.J. Zarnoch, D.A. Abrahamson, and P.M. Dougherty
}

\begin{abstract}
Throughfall and stemflow estimates were obtained on a rain-event basis for small (0.09-hectare) plots established in a young loblolly pine (Pinus taeda L.) plantation in North Carolina. The plots were exposed to specific fertilization and irrigation treatments, which resulted in a wide range of basal areas and leaf area indices.

Coefficients of variation were also determined, which revealed a negative exponential relationship with rain-event magnitude.

Throughfall was substantially less variable than stemflow. Recommended sample-size curves were developed for throughfall and stemflow to achieve 5 percent accuracy at the $0.80,0.90$, and 0.95 probability levels.
\end{abstract}

Keywords: Accuracy, hydrology, sample size, sampling design, variability.

\section{Introduction}

Investigations of global climate change effects on forest ecosystems require an intensive, multidisciplinary research approach. One of the most important components that must be understood in order to predict ecosystem response to global change is the site water balance. Annual and seasonal water balances are some of the major estimators of expected productivity. To obtain good calculations of the hydrologic process, both moisture inputs and losses must be measured or estimated using one or more components such as rainfall. Although numerous experimental techniques have been used for throughfall collection, sampling intensity has been the main source of disparity (Peterson and Rolfe 1979). The desire for statistical precision by using large sample sizes has often been tempered by the reality of economic and sampling time restrictions (Miller and Miller 1976). Loustau and others (1992) found that validation of models used to simulate throughfall and stemflow inputs to the forest floor, which compare predicted to observed values, fail to incorporate the sampling error of measured data such as gross rainfall, throughfall, and stemflow. This paper examines the sampling requirements for throughfall and stemflow in order to accurately characterize rainfall inputs to the forest floor via throughfall and stemflow in loblolly pine (Pinus taeda L.) plantations.

Estimation and prediction of hydrological process variables are fundamentally two distinct problems. Estimation requires sampling methodologies to arrive at an estimate of the parameter for a particular location and rain event. Observations on the hydrological variable are taken on each sampling unit during the rain event and the appropriate parameter estimator is computed along with measures of variability. Prediction requires a regression equation that relates the hydrological variable to one or more predictor variables. The regression equation is developed from data obtained from previous sampling of the hydrological variable, along with predictor variables that include total rainfall and may include stand characteristics such as leaf area index (LAI), basal area (BA), and tree height (Abrahamson and others 1998). Once such a regression is formed, the hydrological variable is merely predicted with the equation for any subsequent rain event, and no sampling of the hydrological variable is required.

Our objective was to evaluate the sampling properties of throughfall and stemflow estimates for young loblolly pine plantations. A simple random sampling design was used for small [0.09-hectare (ha)] research-sized plots. Variability was evaluated and used to develop recommendations on sampling intensity to meet specific precision objectives.

\section{Methodology}

\section{Study Site}

This study was derived from a larger study designed to determine the effects of irrigation and nutrition on loblolly pine growth and stand development in the sandhills of North Carolina (see Abrahamson and others 1998 for more information). The larger study included four treatmentscontrol, irrigated, fertilized, and irrigated plus fertilized — each installed on 0.09-ha plots [ 30 by 30 meters (m)] and replicated four times in a randomized complete block design on a 4-ha study site. Basal area had been standardized across the treatments but, over time, effects of the treatments yielded a wide range of plot BA and LAI. This was ideal for our study of throughfall and stemfow sampling variability under such a diversity of stand characteristics. It increased the scope of inference by widening the range of applicability for sampling recommendations generated by this research. 
Rainfall was measured with a tipping bucket rain gauge placed $2 \mathrm{~m}$ above the soil surface at a weather station located in a 60 - by $60-\mathrm{m}$ clearing adjacent to the study area. Throughfall is rain that reaches the forest floor through spaces in the forest canopy and as drip from the canopy. We sampled it with four randomly located troughs [150 centimeters $(\mathrm{cm})$ by $10 \mathrm{~cm}$ ] positioned $0.75 \mathrm{~m}$ above the ground in each plot. Stemflow is rain that is captured on the canopy and runs down the bole of the trees. We sampled it from four randomly selected loblolly pine trees per plot. Plastic tubing was completely wrapped around the circumference at the base of selected trees and connected to a collecting container. We performed throughfall and stemflow sampling on a rain-event basis from 1992 through 1993. Occasionally, when a plot did not have all four stemflow samples taken, we deleted it from our analysis to maintain equal sampling intensity throughout the study.

\section{Sampling Methodology}

We used a simple random sampling design to gather study data (see Cochran 1977). Simple random sampling consists of selecting $\mathrm{n}$ units out of the population of $\mathrm{N}$ units such that every sample of size $n$ has the same probability

$1 /\left(\begin{array}{l}N \\ n\end{array}\right)=\frac{n !(N-n) !}{N !}$ of being chosen. Let

$\mathrm{N}=$ the total number of possible units in the population,

$\mathrm{n}=$ number of units taken, and

$\mathrm{y}_{\mathrm{i}}=$ observation on unit $\mathrm{i}$.

An estimate of the mean is

$$
\bar{y}=\sum_{i=1}^{n} y_{i} / n,
$$

an estimate of the variance of an observation is

$$
s^{2}=\frac{\sum_{i=1}^{n}\left(y_{i}-\bar{y}\right)^{2}}{n-1}
$$

an estimate of the coefficient of variation of an individual observation is

$$
C V(y)=\frac{100 s}{\bar{y}},
$$

and an estimate of the variance of the estimated mean is

$$
s^{2}(\bar{y})=\frac{s^{2}}{n}\left(1-\frac{n}{N}\right)
$$

Note that the latter differs from the traditional variance of the mean from an infinite population by the factor $\left(1-\frac{n}{N}\right)$, which is the finite population correction. If the sampling fraction is low, e.g., $<5$ percent, the correction is often ignored for simplicity. An approximate $100(1-\alpha)$ percent confidence interval on the population mean is

$$
\bar{y} \pm t_{\alpha / 2(n-1)} s(\bar{y})
$$

where $t_{\alpha / 2(n-1)}$ is the upper $\alpha / 2$ percentage point of the Student's $t$ distribution. If the sample size $\mathrm{n}$ is at least 50, the normal distribution is usually used instead. The coefficient of variation of the estimator is defined as

$$
C V(\bar{y})=\frac{100 s(\bar{y})}{\bar{y}}=\frac{C V(y)}{n^{1 / 2}}\left(1-\frac{n}{N}\right)^{1 / 2}
$$

In designing sampling plans, efficiency can be maximized by determining the required sample size to be within a specified $D$ percent of the true population mean with a specified probability $1-\alpha$. This requires that the half width of the confidence interval for the mean be equal to $\mathrm{D}$ percent of the mean, which when stated mathematically becomes

$$
D=\frac{100 t_{\alpha / 2(n-1)} s(\bar{y})}{\bar{y}}=\frac{t_{\alpha / 2(n-1)} C V(y)}{n^{1 / 2}}\left(1-\frac{n}{N}\right)^{1 / 2}
$$

The researcher chooses $\mathrm{D}$ and $\alpha$ based on perceived accuracy needs $-\mathrm{CV}(\mathrm{y})$ is approximated using a value from previous sampling efforts. Given these three values, the required sample size can be computed from

$$
\frac{N n}{N-n}=\left(\frac{t_{\alpha / 2(n-1) C V(y)}}{D}\right)^{2}
$$

or

$$
n=\left(\frac{t_{\alpha / 2(n-1)} C V(y)}{D}\right)^{2}
$$

if the finite population correction can be ignored for simplicity. Note that this must be solved by iteration because $\mathrm{n}$ is on both sides of the equation.

\section{Study Design}

Simple random sampling methodology was used to estimate the mean and variance for throughfall and stemflow for each plot-rain event (the target population of interest). The four throughfall and stemflow collectors in each plot comprised 
sampling units. The finite population correction was ignored for throughfall because the number of sample units was small relative to the total number that could be used, i.e., $\mathrm{n} / \mathrm{N}$ was $<0.05$. However for stemflow, the number of trees per plot was 100 plus or minus 5 , and the calculated required sample size $\mathrm{n}$ for a specified precision level could often result in $\mathrm{n} / \mathrm{N}>0.05$. Thus, the finite population correction was used.

Because our objective was to obtain recommended sample sizes to meet specific precision requirements, we needed an estimate of variability. So we calculated the coefficient of variation on an observation basis $\mathrm{CV}(\mathrm{y})$ for each plot-rain event. Using equations (9) and (8) we could then determine the sample size necessary for throughfall and stemflow, respectively, in future sampling efforts in order to achieve 5 percent accuracy at the $0.80,0.90$, and 0.95 probability levels over the observed range of rain events. However to achieve this, the $\mathrm{CV}(\mathrm{y})$ must be approximated for a given rain event. Helvey and Patric (1966) show that CV(y) is related to rainevent magnitude in a negative exponential manner, i.e., $\mathrm{CV}(\mathrm{y})$ decreases with increasing rain for a given event. Hence, $\mathrm{CV}(\mathrm{y})$ for throughfall and stemflow were related to rainfall by fitting the negative exponential model

where

$$
C V(y)=a+b e^{\mathrm{c} R A I N}
$$

$\mathrm{a}, \mathrm{b}$, and $\mathrm{c}(\mathrm{c}<0)$ are estimated parameters and $\mathrm{e}$ is the exponential constant equal to 2.7183 .

Note that as rain decreases, $\mathrm{CV}(\mathrm{y})$ approaches $\mathrm{a}+\mathrm{b}$ while as rain increases $\mathrm{CV}$ approaches a. This is the trend reported by Helvey and Patric (1966). Our objective was not to develop a precise prediction model for $\mathrm{CV}(\mathrm{y})$, but to obtain an estimate over a range of rainfall by smoothing out the trend observed in $\mathrm{CV}(\mathrm{y})$ from the study. With such an estimate of $\mathrm{CV}(\mathrm{y})$ for a given anticipated rainfall, the sample size could be calculated from the methods previously discussed.

\section{Results}

Descriptive statistics on variables used in our throughfall and stemflow analyses are given in tables 1 and 2, respectively. Rainfall averaged around 22 millimeters ( $\mathrm{mm}$ ) per rain event with the maximum being $65 \mathrm{~mm}$. Stand conditions over the course of our study are characterized by an average LAI of approximately $0.80 \mathrm{~m}^{2}$ per square meter $\left(0.14 \mathrm{~m}^{2}\right.$ per square meter to $2.26 \mathrm{~m}^{2}$ per square meter) and a BA approximately $2.92 \mathrm{~m}^{2}$ per hectare $\left(0.25 \mathrm{~m}^{2}\right.$ per hectare to
$7.24 \mathrm{~m}^{2}$ per hectare). Rain, throughfall, and stemflow were quite consistent over treatments despite higher LAI and BA for treatments 3 and 4 . However, the $\mathrm{CV}(\mathrm{y})$ for throughfall generally increased with increasing LAI and BA, the overall average being 14.6 percent. Figure 1 illustrates the variation in throughfall $\mathrm{CV}(\mathrm{y})$ with the magnitude of the rain event over all treatments. It indicates large variation with small rain events ( $<25 \mathrm{~mm}$ ) but a constant, smaller CV(y) with larger events. The negative exponential model (10) was fit to the data on an individual treatment basis and then pooled for all treatments. Although the fits had rather low correlation coefficients (r), the models did represent the monotonically decreasing asymptotic relationship of $\mathrm{CV}(\mathrm{y})$ to rain and is very similar to that reported by Helvey and Patric (1966). Although individual parameter estimates varied by treatment (table 3), the pooled model was used to represent the general $\mathrm{CV}(\mathrm{y})$ expected over the complete range of plot conditions (LAI and BA) observed in all four treatments, which renders the conclusions more broadly applicable. Using the samplesize equation (9), the number of collectors needed to sample throughfall at 5 percent accuracy at various probability levels was calculated (fig. 2). Because CV(y) is large when rain is $25 \mathrm{~mm}$ or less, a prohibitive number of collectors are required. However, with rain events over $25 \mathrm{~mm}$, a more reasonable number of collectors is needed. For example, if one wishes to estimate throughfall to within 5 percent accuracy 90 percent of the time, then about 15 collectors are required for an anticipated $25-\mathrm{mm}$ rain event. This is similar to that reported by Helvey and Patric (1966), who suggest 20 for this level of precision.

Variability for stemflow was substantially greater than for throughfall; $\mathrm{CV}(\mathrm{y})$ averaged 39 percent (table 2) with no apparent trend in LAI and BA. With small rain events, CV(y) was large but, unlike throughfall, it diminished only slightly with increasing rain (fig. 3). The negative exponential model had very low correlation coefficients (r) but still represented the monotonically decreasing, asymptotic relationship. Using the pooled model $\mathrm{CV}(\mathrm{y})$, we calculated the required sample size using the finite population correction assuming 100 trees per plot [equation (8)]. The number of collectors needed to sample stemflow at 5 percent accuracy at various probability levels is shown in figure 4 . For example, 47 stemflow collectors are needed to be within 5 percent accuracy 80 percent of the time for an anticipated $25-\mathrm{mm}$ rain event. Because the plot contained 100 trees, almost half the trees must have stemflow collectors. This illustrates the increased level of variability present with stemflow sampling as compared with throughfall. 
Table 1-Descriptive statistics for the throughfall analysis for small (0.09-hectare) research plots

\begin{tabular}{|c|c|c|c|c|c|}
\hline \multirow{2}{*}{$\begin{array}{l}\text { Variable and } \\
\text { statistic }\end{array}$} & \multicolumn{5}{|c|}{ Treatment $^{a}$} \\
\hline & 1 & 2 & 3 & 4 & Pooled \\
\hline \multicolumn{6}{|l|}{ Rain (mm) } \\
\hline Min & 0 & 0 & 0 & 0 & 0 \\
\hline Max & 65 & 65 & 65 & 65 & 65 \\
\hline Mean & 22.7 & 22.6 & 22.5 & 22.6 & 22.6 \\
\hline \multicolumn{6}{|c|}{ Throughfall (mm) } \\
\hline Min & 0 & 0 & 0 & 0 & 0 \\
\hline Max & 62 & 64 & 66 & 65 & 66 \\
\hline Mean & 19.9 & 20.0 & 19.6 & 20.2 & 19.9 \\
\hline \multicolumn{6}{|l|}{$\mathrm{LAI}^{b}\left(\mathrm{~m}^{2} / \mathrm{m}^{2}\right)$} \\
\hline Min & .29 & .29 & .26 & .14 & .14 \\
\hline $\operatorname{Max}$ & 1.34 & 1.32 & 2.01 & 2.26 & 2.26 \\
\hline Mean & .66 & .63 & .94 & .89 & .78 \\
\hline \multicolumn{6}{|l|}{$\mathrm{BA}^{c}\left(\mathrm{~m}^{2} / \mathrm{ha}\right)$} \\
\hline Min & .25 & .29 & .25 & .29 & .25 \\
\hline $\operatorname{Max}$ & 3.68 & 4.03 & 6.51 & 7.24 & 7.24 \\
\hline Mean & 2.15 & 2.24 & 3.54 & 3.70 & 2.91 \\
\hline \multicolumn{6}{|l|}{$\mathrm{CV}(\mathrm{y})^{d}(\%)$} \\
\hline Min & 0 & 1.6 & 0 & .8 & 0 \\
\hline $\operatorname{Max}$ & 70.1 & 140.4 & 127.8 & 83.2 & 140.4 \\
\hline Mean & 12.7 & 12.8 & 16.0 & 17.0 & 14.6 \\
\hline
\end{tabular}

${ }^{a}$ Treatment $1(\mathrm{n}=245)$, treatment $2(\mathrm{n}=202)$, treatment $3(\mathrm{n}=240)$, treatment $4(\mathrm{n}=199)$, pooled $(\mathrm{n}=886)$.

${ }^{b}$ Leaf area index.

${ }^{c}$ Basal area.

${ }^{d}$ Coefficient of variation.

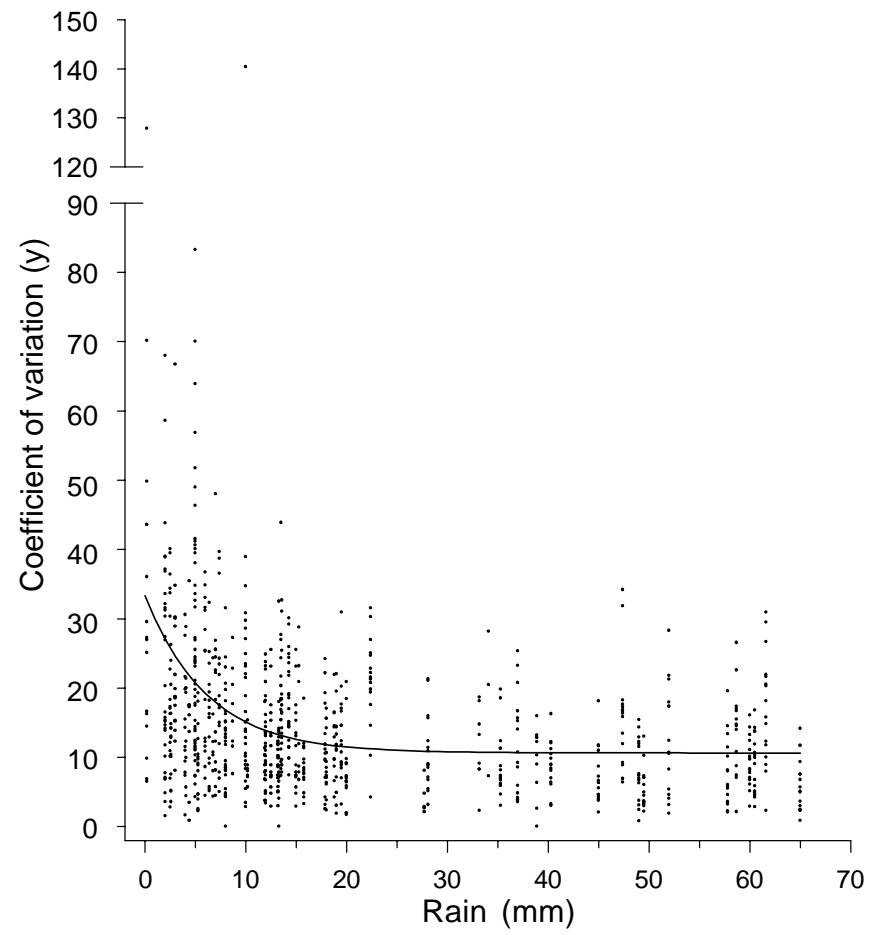

Figure 1-The relationship of the coefficient of variation $\mathrm{CV}(\mathrm{y})$ for throughfall to rain on an event basis for individual small research plots $(0.09$ hectare $)$.
Table 2-Descriptive statistics for the stemflow analysis for small (0.09-hectare) research plots

\begin{tabular}{|c|c|c|c|c|c|}
\hline \multirow{2}{*}{$\begin{array}{l}\text { Variable and } \\
\text { statistic }\end{array}$} & \multicolumn{5}{|c|}{ Treatment $^{a}$} \\
\hline & 1 & 2 & 3 & 4 & Pooled \\
\hline \multicolumn{6}{|l|}{ Rain (mm) } \\
\hline Min & 2 & 2 & 2 & 2 & 2 \\
\hline Max & 65 & 65 & 65 & 60 & 65 \\
\hline Mean & 22.8 & 21.9 & 22.3 & 22.7 & 22.4 \\
\hline \multicolumn{6}{|c|}{ Stemflow $\left(\mathrm{mm}^{2} / \mathrm{ha}\right)$} \\
\hline Min & .015 & .016 & .013 & .013 & .013 \\
\hline Max & 2.980 & 2.853 & 3.102 & 4.761 & 4.761 \\
\hline Mean & .698 & .718 & .785 & .727 & .732 \\
\hline \multicolumn{6}{|l|}{$\operatorname{LAI}^{b}\left(\mathrm{~m}^{2} / \mathrm{m}^{2}\right)$} \\
\hline Min & .33 & .30 & .31 & .14 & .14 \\
\hline Max & 1.34 & 1.32 & 2.01 & 2.13 & 2.13 \\
\hline Mean & .67 & .63 & 1.01 & .89 & .80 \\
\hline \multicolumn{6}{|l|}{$\mathrm{BA}^{c}\left(\mathrm{~m}^{2} / \mathrm{ha}\right)$} \\
\hline Min & .25 & .29 & .40 & .29 & .25 \\
\hline Max & 3.68 & 4.03 & 6.51 & 7.24 & 7.24 \\
\hline Mean & 2.15 & 2.24 & 3.64 & 3.70 & 2.93 \\
\hline \multicolumn{6}{|l|}{$\mathrm{CV}(\mathrm{y})^{d}(\%)$} \\
\hline Min & 9.5 & 5.8 & 9.5 & 5.3 & 5.3 \\
\hline Max & 84.0 & 97.6 & 84.1 & 116.3 & 116.3 \\
\hline Mean & 35.5 & 38.9 & 36.8 & 47.2 & 39.0 \\
\hline
\end{tabular}

${ }^{a}$ Treatment $1(\mathrm{n}=185)$, treatment $2(\mathrm{n}=143)$, treatment $3(\mathrm{n}=166)$, treatment $4(\mathrm{n}=124)$, pooled $(\mathrm{n}=618)$.

${ }^{b}$ Leaf area index.

${ }^{c}$ Basal area.

${ }^{d}$ Coefficient of variation.

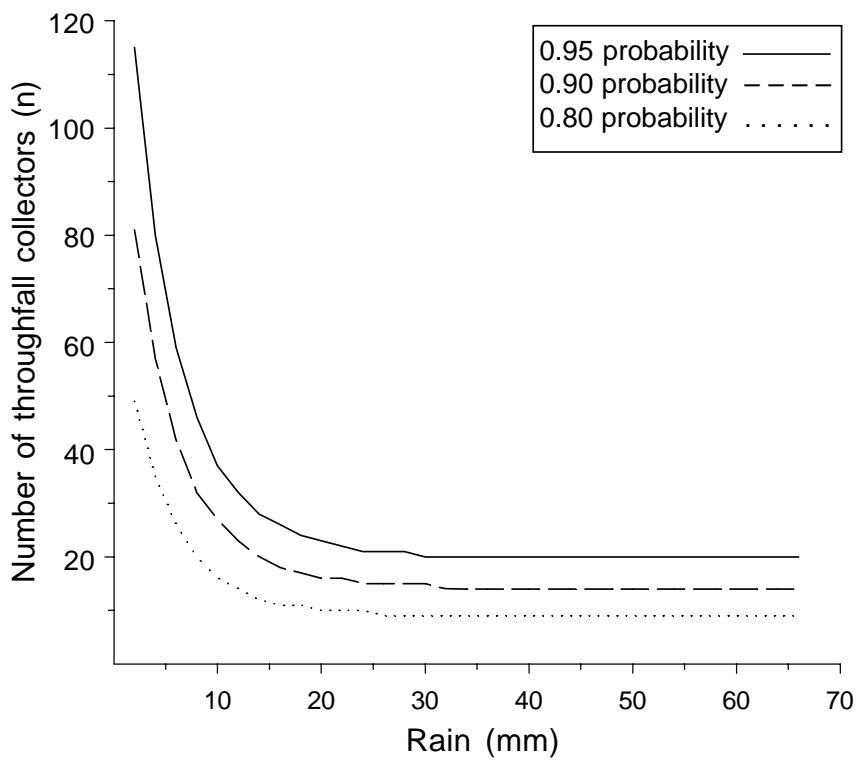

Figure 2-The number of throughfall collectors (n) needed on an event basis to sample throughfall on small research plots $(0.09$ hectare) at 5 percent accuracy and selected probability levels ignoring the finite population correction. 
Table 3-Parameter estimates and fit statistics for the negative exponential model of CV's in throughfall and stemflow to rain for small research plots $(0.09$ hectare $)$

${ }^{b}$ Correlation coefficient

\begin{tabular}{lccccc}
\hline & \multicolumn{5}{c}{ Parameter estimates } \\
\cline { 2 - 6 } Treatment & $\mathrm{a}$ & $\mathrm{b}$ & $\mathrm{c}$ & M.S.E. ${ }^{a}$ & $\mathrm{r}^{b}$ \\
\hline Throughfall & & & & & \\
1 & 8.89 & 25.0 & -0.175 & 64.2 & 0.55 \\
2 & 8.87 & 20.4 & -.155 & 134.0 & .38 \\
3 & 14.1 & 48.7 & -.547 & 123.5 & .50 \\
4 & 11.0 & 17.9 & -.081 & 120.1 & .41 \\
Pooled & 10.6 & 22.7 & -.163 & 114.5 & .43 \\
Stemflow & & & & & \\
1 & 33.7 & 21.6 & -.245 & 259.6 & .18 \\
2 & 36.5 & 85.3 & -.467 & 254.0 & .36 \\
3 & 34.6 & 10.0 & -.105 & 199.0 & .15 \\
4 & 42.6 & 31.0 & -.155 & 620.1 & .22 \\
Pooled & 36.4 & 25.1 & -.208 & 332.5 &. .20 \\
\hline
\end{tabular}

${ }^{a}$ Mean square error.

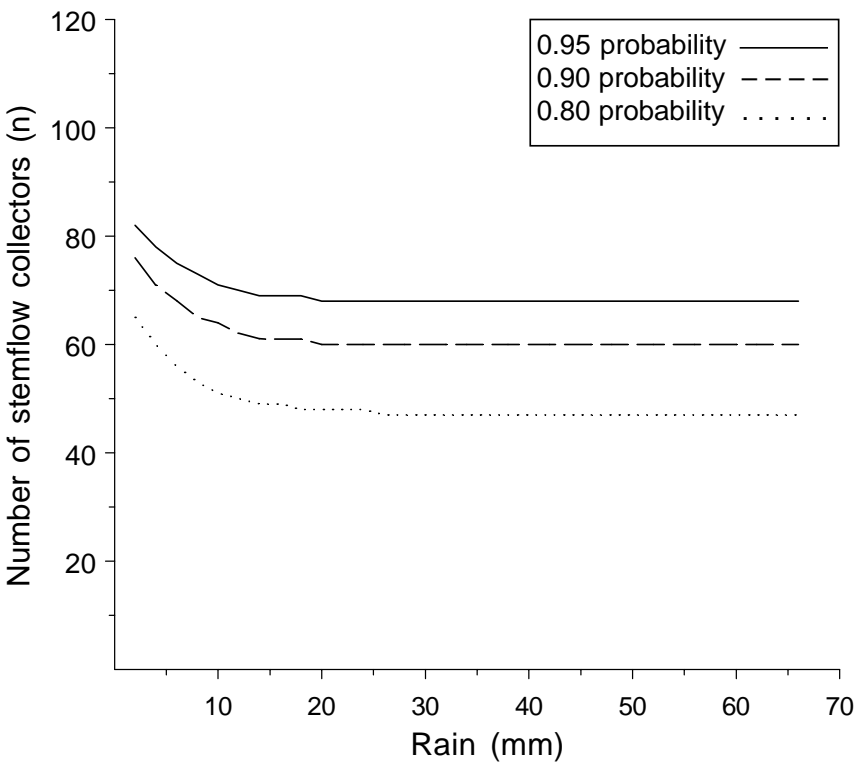

Figure 4-The number of stemflow collectors (n) needed on an event basis to sample stemflow on small research plots $(0.09$ hectare $)$ at 5 percent accuracy and selected probability levels using the finite population correction where it is assumed that there are 100 tree stems on a plot.

\section{Conclusions}

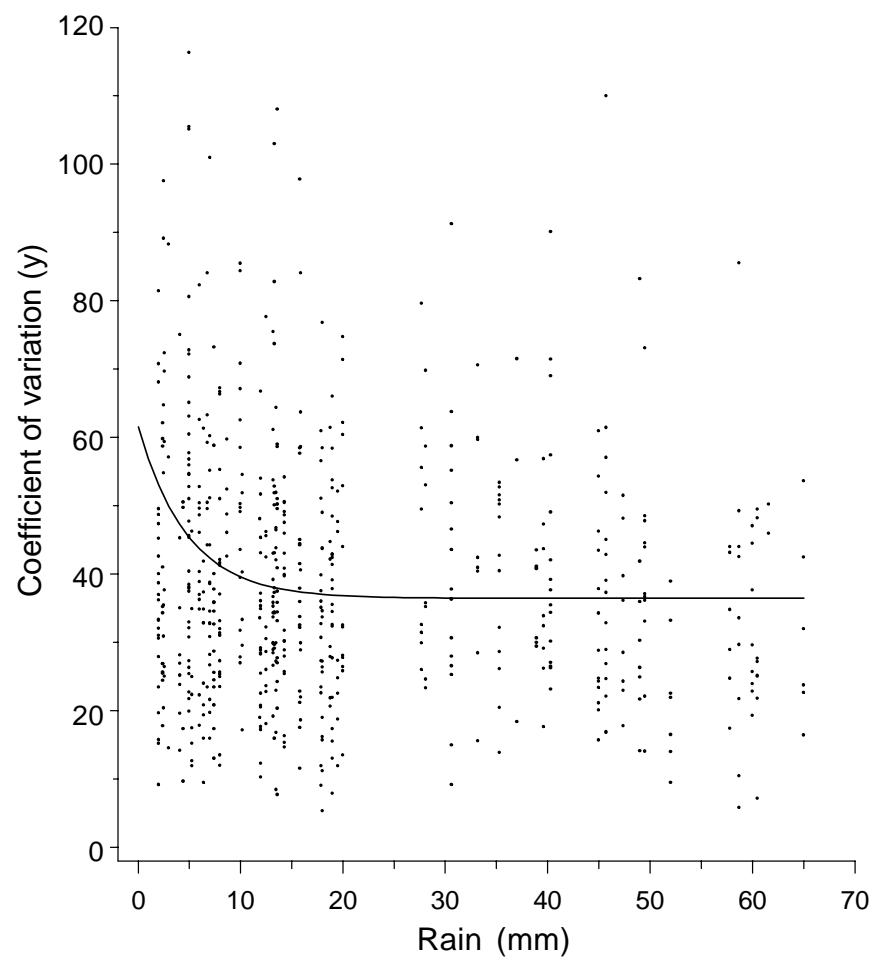

Figure 3-The relationship of the coefficient of variation CV(y) for stemflow to rain on an event basis for individual small research plots (0.09 hectares).
It is apparent that throughfall has an acceptable $\mathrm{CV}$, which is constant with rain events over $25 \mathrm{~mm}$. Thus, the sample-size curves presented should be useful in designing throughfall sampling studies in loblolly pine plantations with similar BA and LAI. However with small rain events, throughfall variability increases substantially, resulting in a doubling or tripling of the required sample size for a 25 -mm rain event.

Stemflow variability was much greater than throughfall and showed little relation with rainfall. Thus, the sample-size curves indicated that at least 50 percent of all trees should probably will not be feasible in most environmental studies.

Our recommended sample sizes are applicable to loblolly pine plantations with BA and LAI similar to those of the plots used in this study, with rainfall up to $65 \mathrm{~mm}$. In addition, trough sizes and stemflow samplers should be similar to those we used. Extrapolation outside of these limits may be risky. In addition, the calculated CV(y)'s from the negative exponential models are predicted values which are subject to considerable variability, reflecting an additional level of uncertainty. Thus, because the CV(y)'s are not known without error, our sample-size recommendations should be interpreted only as guidelines be sampled for any rain event, a recommendation that 
for future studies. However, they are very similar to those of Helvey and Patric (1966), which we find reassuring. If a conservative approach is to be taken for a given study, the researcher should use his or her own judgment and increase the recommended sample size, if possible. The methodology and CV(y)'s presented could easily be used to determine recommended sample sizes for accuracy (D) and probability $(\alpha)$ levels not presented in this paper. Our study emphasizes the importance of sample size, stand conditions, and careful sampling techniques for measuring the hydrological components of throughfall and stemflow to be used in subsequent calculations of soil-water balance.

\section{Acknowledgments}

We thank Andy Laviner, Michelle Canick, Karen Sarsony, and David Josepheus for their excellent and reliable field and lab work; and Dr. Lee Allen and Tim Albaugh for use of their leaf area index and basal area data. We also appreciate the technical reviews provided by Dr. Daniel A. Marion and Dr. Ge Sun, which helped to improve the manuscript. The USDA Forest Service, Southern Global Climate Change Program, funded this project.

\section{Literature Cited}

Abrahamson, D.A.; Dougherty, P.M.; Zarnoch, S.J. 1998. Hydrological components of a young loblolly pine plantation on a sandy soil with estimates of water use and loss. Water Resources Research. 34(12): 3503-3513.

Cochran, W.G. 1977. Sampling techniques. $3^{\text {rd }}$ ed. New York: John Wiley. $428 \mathrm{p}$.

Helvey, J.D.; Patric, J.H. 1966. Design criteria for interception studies. International Association of Science Hydrology Bulletin. 67: $131-137$.

Loustau, D.; Berbigier, P.; Granier, A.; El Hadj Moussa, F. 1992. Interception loss, throughfall and stemflow in a maritime pine stand. I. Variability of throughfall and stemflow beneath the pine canopy. Journal of Hydrology. 138(1992): 449-467.

Miller, J.D.; Miller, H.G. 1976. Apparatus for collecting rainwater in three Minnesota forests. Oikos. 23: 14-22.

Peterson, D.L.; Rolfe, G.L. 1979. Determining sample size in throughfall studies. Forest Science. 25(4): 582-584. 
Zarnoch, S.J.; Abrahamson, D.A.; Dougherty, P.M. 2002. Sampling throughfall and stemflow in young loblolly pine plantations. Res. Pap. SRS-27. Asheville, NC: U.S. Department of Agriculture, Forest Service, Southern Research Station. 6 p.

Throughfall and stemflow estimates were obtained on a rain-event basis for small (0.09-hectare) plots established in a young loblolly pine (Pinus taeda L.) plantation in North Carolina. The plots were exposed to specific fertilization and irrigation treatments, which resulted in a wide range of basal areas and leaf area indices. Coefficients of variation were also determined, which revealed a negative exponential relationship with rain-event magnitude. Throughfall was substantially less variable than stemflow. Recommended sample-size curves were developed for throughfall and stemflow to achieve 5 percent accuracy at the $0.80,0.90$, and 0.95 probability levels.

Keywords: Accuracy, hydrology, sample size, sampling design, variability. 
U4:5

The Forest Service, United States Department of Agriculture (USDA), is dedicated to the principle of multiple use management of the Nation's forest resources for sustained yields of wood, water, forage, wildlife, and recreation. Through forestry research, cooperation with the States and private forest owners, and management of the National Forests and National Grasslands, it strives-as directed by Congress - to provide increasingly greater service to a growing Nation.

The USDA prohibits discrimination in all its programs and activities on the basis of race, color, national origin, sex, religion, age, disability, political beliefs, sexual orientation, or marital or family status. (Not all prohibited bases apply to all programs.) Persons with disabilities who require alternative means for communication of program information (Braille, large print, audiotape, etc.) should contact USDA's TARGET Center at (202) 720-2600 (voice and TDD).

To file a complaint of discrimination, write USDA, Director, Office of Civil Rights, Room 326-W, Whitten Building, 1400 Independence Avenue, SW, Washington, D.C. 20250-9410 or call (202) 720-5964 (voice and TDD). USDA is an equal opportunity provider and employer. 